\title{
Profundidade: uma dimensão vivida pelo corpo ${ }^{1}$
}

\author{
Yasmin Elganim Vieira \\ Mestra pelo Programa de Pós-Graduação em Arquitetura e Urbanismo da UFMG \\ Contato: yasminelganim@gmail.com
}

\section{RESUMO}

Este artigo discute a profundidade numa direção oposta à sua objetividade. Não se trata de discorrê-la como uma habituada coordenada do espaço ou como um parâmetro referente à extensão espacial. Desdobra-se aqui a profundidade num nível subjetivo: como uma dimensão vivida pelo corpo. À luz da fenomenologia do filósofo Maurice Merleau-Ponty (1908-1961) e de sua análise dos planos pictóricos do artista Paul Cézanne (1938-1906), enunciam-se algumas considerações sobre a existência da profundidade como uma dimensão que estrutura a relação CORPO-ESPAÇO. A profundidade subjetiva se torna potencialidade para a disciplina da arquitetura ao ser responsável pelo engajamento corpóreo.

Palavras-chave: Profundidade; Fenomenologia; Merleau-Ponty; Cézanne; Relação CORPO-ESPAÇO.

\section{Depth: a dimension lived by the body}

\begin{abstract}
This article discusses depth in an opposite direction to its objectivity. It is not a matter of discussing it as a familiar coordinate of space or as a parameter referring to spatial extension. In this article, depth is unfolded on a subjective level: as a dimension lived by the body. Based on the phenomenology of the French philosopher Maurice Merleau-Ponty (1908-1961) and on his analysis of the pictorial planes of Paul Cézanne (1938-1906), some considerations are made about the existence of depth as a dimension that structures the body in the space. Subjective depth becomes a potentiality for the discipline of architecture by attributing plasticity to the BODY-SPACE relationship and by being responsible for corporeal engagement.
\end{abstract}

Keywords: Depth; Phenomenology; Merleau-Ponty; Cézanne; BODY-SPACE relationship. 


\section{Limiar: noção CORPO-ESPAÇO}

Antes de desdobrar a profundidade por um viés subjetivo, cabem algumas ponderações sobre a noção CORPO-ESPAÇO. Compreendê-la consiste num ponto de inflexão importante, porque enuncia a indissociabilidade entre corpo e espaço, essencial para a paisagem teórica da fenomenologia em que se baseia este texto.

No pensamento do fenomenólogo francês Maurice Merleau-Ponty (1908-1961) a relação entre corpo e espaço se delineia a partir da existência corpórea no espaço vivido. Melhor, como definem os fenomenólogos, no espaço "anti-predicativo", o espaço da sensação, o vivido pela corporeidade e sensibilidade, organizado no plano perceptivo e não no plano do conhecimento, da técnica ou da razão. A categoria espacial que se expressa aqui se trata do espaço da experiência, que se revela à consciência imediata e nasce da vivência corporal. O que corresponde, em relação à categoria do corpo, ao ser sensível, que em sua condição se exibe como estesiológico, dotado de sentidos e sensibilidade, como sinestésico, inteiramente engajado e solicitado no funcionamento de cada sentido, e como cinestésico, dotado de movimento contínuo. Na fenomenologia, a relação CORPO-ESPAÇO se substancia de estofo experimental, condicionada por um corpo perceptivo e em situação.

Dentre outras questões, o filósofo buscou a originalidade e a essência dessa relação e encarregou-se de atribuir uma condição à existência corpórea essencialmente espacial. Para Merleau-Ponty (2011, p. 205) "ser corpo [...] é estar atado a um certo mundo, e nosso corpo não está primeiramente no espaço: ele é no espaço". O espaço está enraizado na existência corpórea, que não repousa sobre si mesma, porque o corpo existe no espaço, sendo o meio pelo qual existir se torna possível. Há uma questão existencial: o corpo existe enquanto sujeito do espaço, que o desperta para a consciência de estar no mundo, e o espaço existe enquanto fundo para a experiência corpórea nascer, o que faz com que o seu sentido seja construído pelo corpo, fazendo-se um receptáculo de significados.

Uma expressão de Merleau-Ponty (2011, p. 273) define essa relação: o corpo está no espaço "assim como o coração no organismo; ele mantém o espetáculo visível continuamente em vida, anima-o e alimenta-o interiormente, forma com ele um sistema" (MERLEAU-PONTY, 2011, p. 273). Em outras palavras, conforma uma relação de interdependência: o corpo precisa do espaço para existir e o espaço ganha sentidos a partir do corpo. Isso quer dizer que o corpo está no espaço assim como o espaço está no corpo. A interioridade corpórea se encontra exposta à exterioridade espacial, assim como o inverso.

Assim, a noção CORPO-ESPAÇO se torna aqui uma relação de elo. O hífen carrega consigo contato, inseparabilidade e mutualidade. É nesse sentido que a profundidade subjetiva pode ser uma chave interpretativa para compreender o como dessa relação. Por meio dessa dimensão, o corpo se ancora ao espaço ao mesmo tempo em que o espaço se revela ao corpo.

\section{Desdobramento da profundidade subjetiva}

Não marcar nenhum contorno seria tirar a identidade dos objetos. Marcar apenas um seria sacrificar a profundidade, isto é, a dimensão que nos oferece a coisa, não como estirada diante de nós, mas repleta de reservas, realidade inesgotável. É por isso que Cézanne vai seguir por uma modulação colorida a intumescência do objeto e marcará em traços azuis vários contornos. (MERLEAU-PONTY, 2004a, p. 117)

O ponto de partida da reflexão exposta se consolida a partir da epígrafe acima, redigida por Merleau-Ponty em seu clássico ensaio A dúvida de Cézanne (MERLEAU-PONTY, [1945] 2004c). Nessa assertiva, Merleau-Ponty enuncia, trabalhada no sensível, o que significa a profundidade: uma dimensão que oferece ao homem a "coisa", ou seja, proporciona tudo o que existe em seu entorno, seja o espaço, os objetos, a natureza. E, ainda, como aquilo responsável por tornar essa relação do homem com as coisas inesgotável, atualizada a todo instante.

Essa abordagem da profundidade não se trata de uma habituada coordenada espacial, uma simples terceira dimensão que constitui o espaço equivalente ao seu volume ou de um parâmetro referente à extensão espacial. Entende-se que a profundidade, descrita acima, existe a priori, anterior a essas objetivações. Merleau-Ponty, enquanto filósofo que se dedicou à fenomenologia, descreveu a profundidade como fenômeno. Quer dizer, como essa dimensão se revela ao corpo, de que maneira o homem se relaciona com a sua natureza aparente, qual sua essência e propósito para a existência. A profundidade, por esse viés, se dá no espaço da experiên-

Revista online do Departamento de Arquitetura e Urbanismo da Pontifícia Universidade Católica do Rio de Janeiro - PUC-Rio, Brasil Ano 8 - No 9 - ISSN 2446-7340 
cia, o "anti-predicativo", atrelada aos sentidos humanos e à consciência imediata.

$\mathrm{Na}$ busca de compreender a estrutura espacial e sua relação com o corpo, na tentativa de retratar o "contato original" de ambos e da "descrição da nossa experiência tal como ela é”, Merleau-Ponty se debruçou sobre a profundidade. Privilegia-se um único recorte de sua filosofia com o objetivo de colocar em relevo a originalidade de seu pensamento sobre essa dimensão. Sua reflexão não se deu apenas no espaço real, o espaço pictórico também foi tema de suas análises. A arte não serviu apenas como um modo do filósofo fundamentar sua filosofia, foi também um meio de compreender e refletir. À vista disso, escreveu, fazendo suas as palavras do artista Alberto Giacometti (1901-1966): “o que me interessa em todas as pinturas é a semelhança, isto é, o que para mim é a semelhança: o que me faz descobrir um pouco o mundo exterior" (MERLEAU-PONTY, 2004b, p. 19). A arte era para Merleau-Ponty como uma operação reflexiva das relações constitutivas das coisas e, principalmente, a de Paul Cézanne (1839-1906), que era um estudo preciso das aparências. A vida de Cézanne não foi marcada por dúvidas ou incertezas, mas por um exercício de procura infindável pela profundidade.

Assim, da assertiva iniciada no texto se deriva, primeiramente, um papel fundamental que a profundidade exerce no que diz respeito à relação CORPO-ESPAÇO: dar o espaço ao corpo. Dito de outro modo, a profundidade oferece, proporciona o espaço para o corpo. Isso ocorre porque ela faz eclodir o corpo no espaço, se faz responsável pelo seu "aqui", fornece a sua situação, única a cada um. Como um eco, essa dimensão desperta a facticidade espacial. Nas palavras de Merleau-Ponty (2011, p. 146), a profundidade "designa a instalação das primeiras coordenadas, a ancoragem de um corpo ativo, a situação do corpo em face de suas tarefas”. Nesse sentido, pode-se concluir que, ao enunciar que o corpo está no espaço, a profundidade se torna responsável, simultaneamente, pelo revelamento espacial. Ao fazer surgir o ponto de vista do corpo, essa dimensão se exibe como a própria condição de existência do espaço. A profundidade significa o meio, o modo que o corpo possui para tê-lo, fazendo com que ele nasça e se abra ao seu redor. Por isso, ela não se trata apenas do volume espacial, uma terceira dimensão que constitui o espaço, mas a sua deflagração em referência a cada corpo.

Essencial, a profundidade se faz responsável pelo entrelaçamento, pelo encontro, pelo contato, pela comunicação, pela estruturação e fundamentação da relação CORPO-ESPAÇO, atestando a indissociabilidade entre ambos. A profundidade se manifesta antes de qualquer objetivação como uma dimensão subjetiva, presente no "mundo vivido", na fundação da experiência corpórea. Por meio dessa dimensão, o espaço se revela ao corpo e o corpo se ancora ao espaço. Com efeito estrutural, ela "revela imediatamente o elo do sujeito ao espaço" (MERLEAU-PONTY, 2011, p. 360) e faz com que essa relação exista.

[...] é preciso redescobrir sob a profundidade como relação entre as coisas ou mesmo entre planos, que é a profundidade objetivada, destacada da experiência e transformada em largura, uma profundidade primordial que dá seu sentido àquela [...], existe uma profundidade que ainda não tem lugar entre os objetos, que, como mais forte razão, não avalia ainda a distância de um a outro, e que é a simples abertura da percepção [a comunicação entre CORPO-ESPAÇO] [...]. (MERLEAU-PONTY, 2011, p. 359)

Outro papel da profundidade, retornando à epígrafe inicial, refere-se ao revelamento do espaço ao corpo realizado por essa dimensão, que ocorre de modo infindável. A profundidade faz com que o espaço nunca cesse de ser apresentado ao corpo. Por mais que esse se mova, mude sua situação, o espaço nunca deixa de se revelar e de existir de acordo com o seu "aqui". A profundidade faz com que a relação CORPO-ESPAÇO se atualize e nunca pare de acontecer, tornando-se inesgotável.

É esse revelamento inesgotável que Cézanne, ao buscar o volumoso do objeto, por meio dos contornos azuis, retrata e que descreve Merleau-Ponty. Pode-se observar que os planos pictóricos cézanneanos não exibem um espaço construído com sequência de planos, ponto de fuga e linha do horizonte. Não há possibilidade de percepcionar o seu quadro por meio de uma visão instantânea e imóvel, porque o olhar escorrega por todo o plano (Figura 1). Isso acontece, segundo Merleau-Ponty (2004a, p. 117), porque Cézanne cria "deformações de perspectiva":

[...] o gênio de Cézanne consiste em fazer com que as deformações de perspectiva, pela disposição de conjunto do quadro, deixem de ser visíveis por si mesmas na visão global e contri-

Revista online do Departamento de Arquitetura e Urbanismo da 
buam apenas, como ocorre na visão natural, para dar impressão de uma ordem nascente, de um objeto que surge a se aglomerar sob o olhar. (MERLEAU-PONTY, 2004a, p. 117)

Além de ligar os contornos de modo quase infinito entre si, sem permitir uma circunscrição finita, Cézanne deforma, então, a densidade do plano. Contemplando-os, pode-se deduzir que ele os deforma como se criasse focos variados e entrelaçados que se movem para mover o espectador. A profundidade surge por vias composicionais, impossibilitando uma síntese completa. Cézanne pinta, na verdade, uma multiplicidade de perspectivas para serem produzidas incessantemente pelos sucessivos deslocamentos do olhar. Tudo isso para que não haja estaticidade e o espaço nunca pare de nascer e de se revelar ao espectador. É nesse sentido que a profundidade germina sobre a pintura de Cézanne: os seus planos se interpenetram e mostram o nascimento sempre continuado do espaço quando o corpo o percebe, tal como ocorre na realidade vivida.

Geralmente descreve-se o fenômeno da profundidade por relações definidas geradas na imagem ótica, tais como a convergência dos olhos e a grandeza aparente das coisas. Essas concepções são descritas pelos clássicos da filosofia do Empirismo e do Intelectualismo como signos da profundidade, e pela psicologia da forma Gestalt como causas. Ao contrário disso, Merleau-Ponty (2011) explica, primeiramente, que a convergência e a grandeza aparente não poderiam ser signos, porque a profundidade não se configura em algo pré-existente. O signo não pode introduzir o corpo na reali-

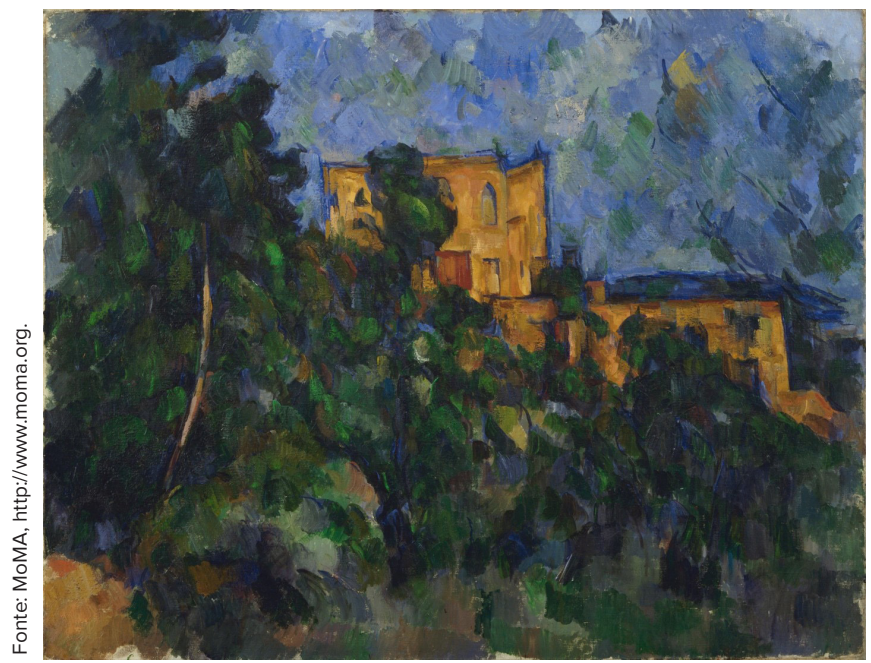

Figura 1. Paul Cézanne, Château Noir, óleo sobre tela, $73.6 \times 93.2 \mathrm{~cm}$, 1903-04. dade espacial, pois esses só "podem introduzir o sujeito na significação do espaço se eles já forem apreendidos" (MERLEAU-PONTY, 2011, p. 346). E não poderiam ser as causas da profundidade, posto que não as implicam. Essa dimensão não condiciona a convergência dos olhos e a grandeza aparente, pelo fato de que uma experiência nunca pode ser correlacionada a condições causais. "Ter a experiência de uma estrutura não é recebê-la em si passivamente: é vivê-la, retomá-la, assumi-la, reencontrar seu sentido imanente" (MERLEAU-PONTY, 2011, p. 348). Ainda, a profundidade não está relacionada com postulados causais, como uma relação de causa-efeito, porque não se trata apenas do espaço se organizar em profundidade, existe também uma participação do sujeito na sua construção, pois ela "nasce sobre o meu olhar porque ele procura ver alguma coisa” (MERLEAU-PONTY, 2011, p. 354).

Para Merleau-Ponty (2011, p. 348-349), a grandeza aparente e a convergência dos olhos são partes integrantes da profundidade e "estão presentes na experiência da profundidade como o motivo", que significa "um antecedente que só age por seu sentido", sendo "a decisão que afirma esse sentido como válido é o que lhe dá sua força e eficácia”. Ambas são condições para uma atitude, e a decisão do corpo de viver a experiência lhe dá eficácia e sentido. Ambas são fenômenos que pertencem ao agir e formam simplesmente a situação do corpo no espaço, isto é, são os efeitos de ser corpo no espaço. O que se abre diante do homem exprime o seu modo de olhar enquanto o olha. A realidade espacial demonstra elasticidade e as ilusões fazem parte da existência corpórea espacial, que não depende, não obedece às leis da geometria.

Nós temos o objeto que se distancia, não deixamos de "possuí-lo" e de ter poder sobre ele, e a distância crescente não é, como a largura parece sê-lo, uma exterioridade que cresce; ela exprime apenas que a coisa começa a escorregar sob a apreensão de nosso olhar, e que ele a esposa menos estritamente. [...] Foram sobretudo as ilusões referentes à profundidade que nos habituaram a considerá-la como uma construção do entendimento. (MERLEAU-PONTY, 2011, p. 353-354)

Num exemplo citado pelo filósofo, quando o corpo olha uma estrada reta e muito extensa, parece enxergar suas margens convergirem ao longe para um mesmo ponto, mesmo que o indivíduo saiba que essas duas retas paralelas em ne-

Revista online do Departamento de Arquitetura e Urbanismo da Pontifícia Universidade Católica do Rio de Janeiro - PUC-Rio, Brasil Ano 8 - No으 9 - ISSN 2446-7340 
nhum momento se cruzarão. Essa deformação virtual faz com que o corpo esteja na estrada, exibindo a sua própria intenção. Nesse sentido, "não se deve dizer nem que as margens da estrada me são dadas como convergentes, nem que me são dadas como paralelas: elas são 'paralelas em profundidade'” (MERLEAU-PONTY, 2011, p. 351). Ou numa outra situação, quando se questiona que um homem a duzentos metros é menor que um visto mais próximo, ele se torna menor ao ser isolado do contexto percebido e medir-se a grandeza aparente. De outra maneira, ele não é nem menor, nem igual em grandeza: ele está aquém do igual e do desigual, ele é o mesmo homem visto de mais de longe.

Toda a argumentação merleau-pontyana conduz à conclusão de que a grandeza aparente, a convergência e as deformações apenas demonstram como o corpo transforma virtualmente a realidade espacial e como o espaço se encontra imerso numa operação sempre constituinte. Tal sistemática demonstra uma questão essencial para a discussão deste texto: a plasticidade presente inerentemente na relação CORPO-ESPAÇO. A profundidade fenomenológica descreve o indício plástico contido inerentemente na condição corpórea com o espaço: o corpo o sentindo sensivelmente como algo em constante transformação. Essa é a tônica dessa dimensão existencial: a dinamicidade da relação CORPO-ESPAÇO. A profundidade fundamenta a capacidade do corpo de en-formar, trans-formar e de-formar a sua realidade espacial, de vivenciar seu metamorfoseamento. Conforma uma relação de construtividade do corpo para com o espaço: o corpo forma o espaço. Dissolve a ideia de espaço como uma unidade "indeformável" para uma experiência espaço-temporal "deformável”, a encenar o corpo estruturando o espaço e o espaço sendo estruturado pelo corpo.

É por isso que Cézanne deforma a perspectiva e, consequentemente, a aparência do plano: para demonstrar a realidade plástica e expressar a densidade da solidez do espaço a se formar junto do olhar do espectador. Num plano fluído, ele exala metamorfose e a evanescência das formas, porque apenas as deformações são capazes de dar a impressão da plasticidade. Como escreve Merleau-Ponty (2004b, p. 40), o plano de Cézanne fornece aos olhos do espectador o que os movimentos reais fornecem: "visões instantâneas em série, convenientemente baralhadas, mostrando, no caso de um ser vivo, atitudes instáveis suspensas entre um antes e um depois, em suma, as aparências da mudança de lugar que o espectador leria no seu rastro". Isso quer dizer que o movimento do olhar nos planos cézanneanos passa a não se exi- bir em termos representacionais, mas se torna intrínseco, realiza a formação do plano. Cézanne marca os objetos com vários contornos na cor azul, para que essa aglomeração de linhas permita que o olhar vaze, movimente-se entre os elementos do plano para formá-lo (Figura 2).

Contudo, ressalta-se que a aparência do espaço se abre "sob a condição de saber que existe um mundo de objetos indeformáveis, que me assegura um estado que sempre garante um retorno" (MERLEAU-PONTY, 2011, p. 346). O corpo pode se relacionar e mudar a aparência do espaço, porque sempre há um retorno ao seu estado constituído, a aparência não se distorce sob sua distorção. Ademais, porque o visível "não é um pedaço de ser absolutamente duro, indivisível, oferecido inteiramente nu a uma visão que só poderia ser total ou nula, mas antes é uma espécie de estreito entre horizontes exteriores e horizontes interiores sempre abertos" (MERLEAU-PONTY, 200o, p. 129). O olhar permite conectar e desconectar as coisas ininterruptamente, porque ele não se exibe como uma totalidade fechada e estática, e sim uma cristalização momentânea da visibilidade, que cria uma modulação efêmera das coisas e do espaço e, assim, está sempre a tocar e ressoar outros pontos.

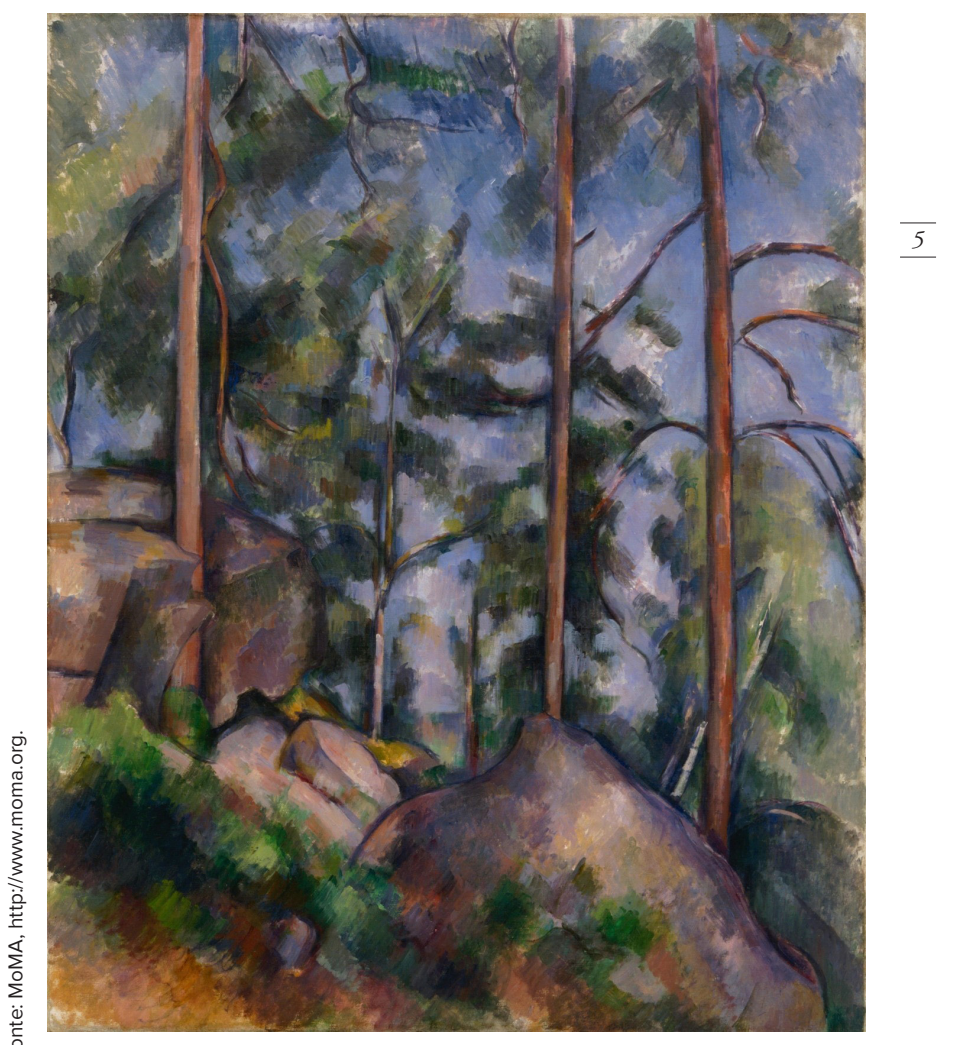

Figura 2. Paul Cézanne, Pines and Rocks, óleo sobre tela, 81.3 ×65.4 cm, 1897. 
A plasticidade, além de fundamentar a dinamicidade entre CORPO-ESPAÇO, comprova o toque recíproco entre ambos. A deformação da aparência exprime a realidade espacial plástica, no entanto, ao mesmo tempo, para que essa plasticidade aconteça, ela exige um corpo para ativá-la, vivê-la, formá-la e, principalmente, modificá-la continuamente. É nesse sentido que Merleau-Ponty (2004a, p. 117) escreve que a profundidade "nos oferece a coisa, não como estirada diante de nós, mas repleta de reservas”. A profundidade dá um espaço entorno do corpo, porque traz um espaço para ele formar e alterar a sua realidade. Implica-o a fazer parte daquilo que o espaço exterioriza, fazendo-o existir como parte integrante. A profundidade dá um espaço que "eu não o vejo segundo seu envoltório exterior, vivo-o por dentro, estou englobado nele" (MERLEAU- PONTY, 2004b, p. 33).

O corpo realiza o desdobramento e a formação da sua realidade espacial e possui em sua condição originária a capacidade de ser matriz para cada outro espaço existente. Isso emana gênese, começo, origem. O corpo cria, forma o seu espaço, o espaço da sua experiência, que pode ser denominado de espaço corporal, "o fundo sobre o qual pode destacar-se ou o vazio diante do qual o objeto pode aparecer como meta de nossa ação" (MERLEAU-PONTY, 2011, p. 149). O corpo carrega consigo o seu espaço, suas próprias propriedades espaciais: cima, baixo, direita, esquerda, simetria, dissimetria.

Ainda, a plasticidade apresenta o caráter dual do espaço, que "está já constituído, mas também não está nunca completamente constituído. Sob o primeiro aspecto, somos solicitados, sob o segundo somos abertos a uma infinidade de possíveis" (MERLEAU-PONTY, 2011, p. 608). Pela profundidade, o espaço se modela na instabilidade, fugaz, movediço, em constante metamorfose.

O espaço não é um ambiente (real ou lógico) em que as coisas se dispõem, mas o meio pelo qual a posição das coisas se torna possível. Quer dizer, em lugar, de imaginá-lo como espécie de éter no qual todas as coisas mergulham, ou de concebê- lo abstratamente com um caráter que lhe seja comum, devemos pensá-lo como potência universal de suas conexões. (MERLEAU-PONTY, 2011, p. 328)

A profundidade faz com que o corpo não esteja no espaço como se estivesse dentro de uma caixa numa relação de continente e conteúdo, mas encaixados numa relação de participação e conformidade. Não há anulação entre eles, mas uma troca, em que um participa da existência do outro. A relação CORPO-ESPAÇO se trata de uma relação visceral em que ambos estão na mesma ordem, num continuum.

\section{Engajamento corpóreo}

Como a profundidade fenomenológica estrutura a relação CORPO-ESPAÇO? Como a faz ser entrelaçada, plástica e inesgotável? Como dá o espaço ao corpo? A resposta se encontra na sua capacidade de engajar o corpo no espaço e, por isso, essa dimensão consegue fundamentar e atualizar essa relação. Uma questão essencial para esclarecer e compreender como ela realiza o engajamento corpóreo se encontra na sua condição de distância.

Ao dar o espaço ao corpo, a profundidade o oferece por meio de uma estrutura de distância, que se mostra muito além de ser uma singela e banal impressão de distanciamento que se abre diante do corpo. Como afirma Georges Didi-Huberman (2010, p. 163), "na profundidade, o espaço se dá - mas se dá distante, se dá como distância”. O corpo recebe o espaço pela profundidade por uma distância que se abre diante dele - denominado aqui de espaço longínquo-visível. No entanto, além de dar esse espaço longínquo-visível como distância, à distância, a profundidade "se retira e num certo sentido se dissimula, sempre à parte, sempre produtora de um afastamento ou de um espaçamento" (DIDI-HUBERMAN, 2010, p. 163). Ou seja, a profundidade está sempre a construir essa distância.

Pode-se dizer, com efeito, que o objeto visual, na experiência da profundidade, se dá à distância; mas não se pode dizer que essa distância ela mesma seja claramente dada. $\mathrm{Na}$ profundidade, o espaço se dá - mas se dá distante, se dá como distância, ou seja, ele se retira e num certo sentido se dissimula sempre à parte, sempre produtor de um afastamento ou de um espaçamento. O que vem a ser portanto essa distância frontalizada, se posso dizer, essa distância apresentada diante de nós e retirada ao mesmo, que chamamos de profundidade? (DIDI-HUBERMAN, 2010, p. 163)

Essa distância incessante existe devido a como o corpo se movimenta, o distanciamento que se abre diante dele se torna praticamente infindável. Ao se mover, o corpo modifica inesgotavelmente a sua relação com o espaço e, conse-

Revista online do Departamento de Arquitetura e Urbanismo da Pontifícia Universidade Católica do Rio de Janeiro - PUC-Rio, Brasil Ano 8 - NNo 9 - ISSN 2446-7340 
quentemente, a profundidade, para continuar a oferecê-lo e proporcionar esse encontro, precisa apresentar uma distância diante do corpo e retirá-la simultaneamente para que seja possível dá-lo novamente. Isto é, a profundidade precisa engajar o corpo incessantemente no espaço para conseguir atualizar o seu "aqui" e continuar a fornecer a sua situação.

Não obstante, para o engajamento corpóreo ocorrer, além de dar o espaço longínquo-visível, a profundidade dá o espaço próximo-tangível, dado sob os pés. O espaço longínquo-visível se dá à distância sob um fundo de ausência, que está sempre a desaparecer, a vibrar com toda efemeridade para que o corpo, ao olhá-lo, possa transformá-lo, por meio do movimento, em seu espaço próximo-tangível. A profundidade necessita dar de modo simultâneo e oscilante esses dois espaços para realizar o engajamento do corpo. Quando Merleau-Ponty (2011, p. 354) dizia que a profundidade "nasce sob o olhar que busca", é segundo "um corpo absorvido em suas tarefas e suscetível de um movimento". Somente por estar orientado para o mundo e por tender no desejo para aquilo que não possui, que o corpo se engaja e a profundidade consegue continuar a proporcionar o espaço.

A profundidade situa o corpo no espaço ao mesmo tempo numa proximidade absoluta e numa distância irremediável. Pela simultaneidade e oscilação do longínquo-visível e do próximo-tangível, ela se torna responsável pelo engajar do corpo e faz nascer, incessantemente, a sua comunicação com o espaço. Isso torna o perceber do espaço uma conquista incansável da distância diante do corpo, que não demonstra ser uma medida métrica de uma coisa à outra, mas se exibe antes como uma distância vivida. Permeada por uma distância incessante, contínua, infindável e totalmente elusiva, a profundidade faz o encontro entre o corpo e o espaço se fecundar numa construção fugaz. Essa dimensão constrói a solidez dessa relação, ancora o corpo no espaço e, simultaneamente, está sempre a desconstruindo, posto que esse seja o único modo de manter o engajamento corpóreo.

Para ocorrer o engajamento do corpo pelo espaço longínquo-visível, esse deve ser permeado de uma obscuridade que interrogue o corpo no ir e vir dos intervalos dos espaços que a profundidade constrói. O espaço longínquo-visível precisa interrogar, inquietar de algum modo o corpo. É nesse sentido que Merleau-Ponty (2011, p. 359) escreve que para a profundidade subjetiva estar verdadeiramente implicada na relação CORPO-ESPAÇO e fazê-la plástica precisa produzir voluminosidade: a "expressão de sua essência qualitativa".
A voluminosidade, segundo Didi-Huberman (2012, p. 165), conjuga "o volume tátil ou construído e a luminosidade ótica incircunscritível”. O volume tátil se trata do sentimento do nascimento do volume do espaço para o corpo e de sua tangibilidade, da possibilidade de ele existir sob os seus pés e de ser possível percorrê-lo. Quanto à luminosidade, conforma uma "obscuridade" no longínquo-visível, uma "falta de clareza”, uma instabilidade para determinar suas circunscrições, seus limites, ou seja, uma "inquietude" quanto ao seu modo de aparição.

A profundidade, com a simultaneidade e a oscilação do espaço longínquo-visível e do espaço próximo-tangível, pode ser relacionada aos modos como Walter Benjamin (18921940), em seu texto $A$ obra de arte na era da reprodutibilidade técnica ([1936] 2013), cita os modos de percepção da arquitetura e, nesse sentido, pode fomentar discussões para essa disciplina. Segundo Benjamin (2013, p. 95), as "construções são recebidas duplamente: pelo uso e pela percepção. $\mathrm{Ou}$ melhor: tátil e opticamente". A modalidade tátil do espaço arquitetônico geralmente se dá pelo hábito, se tratando da experiência geral, comum e compartilhada coletivamente, vivida no tempo real e cotidiano de modo distraído quando se habita o espaço. No caso da óptica, essa gera mais atenção e contemplação, o que exige do habitante um momento de suspensão de seu percurso. Relacionando seu pensamento com os espaços dados pela profundidade, o espaço próximo-tangível seria mais usado pela distração e o espaço longínquo-visível corresponderia a uma suspensão do percurso do habitante para uma possível contemplação.

Assim, o grande mérito da simultaneidade e oscilação dos espaços dados pela profundidade estaria em equilibrar justamente a distração e a contemplação espacial colocados por Benjamin. O modo do uso do espaço condiciona o modo como o habitante o verá, mas o que o habitante vê também condiciona o uso. Algo deve despertar a sua atenção em seu visível, de tal modo que queira se mover para examiná-lo. Isso quer dizer que engajar o corpo significa tensionar na arquitetura o espaço longínquo-visível e o espaço próximo-tangível, e fazer cada habitante se sentir mobilizado por aquilo que vê. Tem a ver com instituir um espaço arquitetônico relativo ao corpo sinestésico implicado em um tempo duradouro, para equilibrar distração e contemplação.

Por fim, ressalta-se que a profundidade coloca a cinestesia como fator constitutivo da relação CORPO-ESPAÇO. O movimento a transpassa em dois pontos que se auto susten-

Revista online do Departamento de Arquitetura e Urbanismo da 
tam. Primeiramente, quando a profundidade dá o espaço longínquo-visível ao corpo, o olhar tem a função de despertar o movimento para a atualização dos espaços, o que faz o olhar estar a cargo de engajar todo o corpo, de ritmar e reger seu movimento, encenando sua sinestesia. Por outro lado, a profundidade também precisa estar alterando a situação do corpo, fazendo com que este se movimente, para que ele sinta o espaço se formar e se transformar virtualmente.

E ao resultar sempre de uma apreensão dinâmica, a profundidade faz o corpo, pelo movimento, habitar simultaneamente o espaço no tempo. Além de uma questão espacial, a profundidade se exibe como uma apresentação do tempo, mas não em um desdobramento progressivo, linear, como uma duração determinada e contínua, e sim como um campo aberto e poroso. Isso porque para se configurarem num processo contínuo de reestruturação, contendo nele mesma a possibilidade de sua transformação, a profundidade organiza a relação CORPO-ESPAÇO num fluxo de uma descontinuidade na continuidade, com fluxo incessante e ruptura instantânea, movimento e contra-movimento. A temporalidade da relação CORPO-ESPAÇO se faz na quebra, na alteração, na interrupção.

Em um último olhar sob os planos cézanneanos, observa-se como o pintor capta o movimento do olhar que abarca essa condição temporal. Cézanne não faz senão criar interrupções na duração contínua do olhar do observador para formar imagens que sejam rupturas para novos encontros e, por isso, consegue fazer com que o espectador e a obra se entrelacem e se desentrelacem incessantemente, num fluxo de

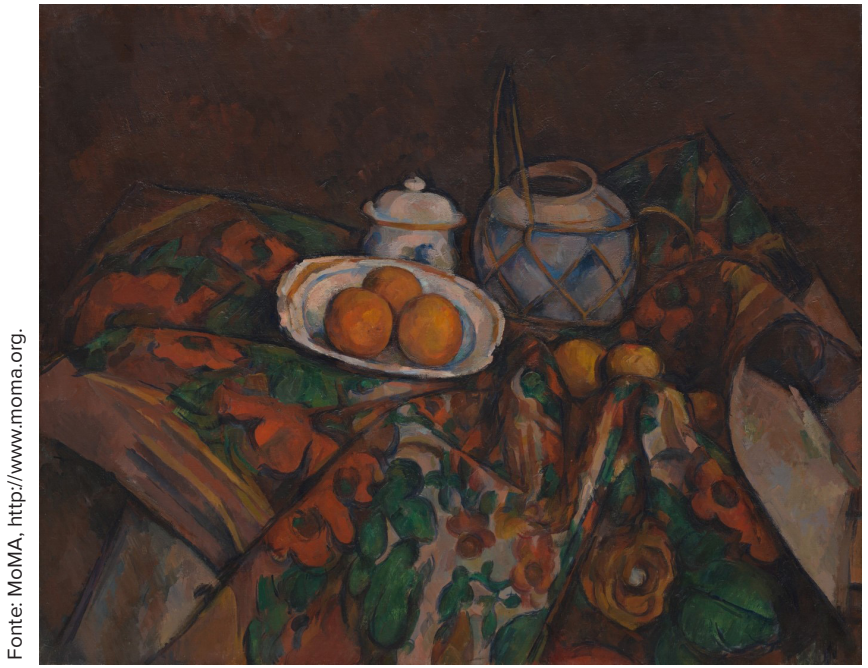

Figura 3. Paul Cézanne, Still Life with Ginger Jar, Sugar Bow and Oranges, óleo sobre tela, $60.6 \times 73.3 \mathrm{~cm}, 1902-06$. uma descontinuidade na continuidade. Isso leva a concluir que ele cria, no plano, o próximo e o longínquo, e faz a visão ser conduzida pelo ritmo das formas e das cores para se perder para se encontrar novamente. Sua pintura produz aproximações e também distanciamentos que interrogam, produzem alguma obscuridade e envolvem o espectador continuamente em toda a duração da contemplação (Figura 3).

\section{Fechamento}

Portanto, a profundidade faz a relação CORPO-ESPAÇO ser entrelaçada (elo) plástica (transformável) e inesgotável (atualizada a todo instante) e exibe a capacidade do corpo de formar o espaço e do espaço ser formado pelo corpo. Sob um pensamento objetivo, há uma experiência pré-objetiva, na qual a profundidade se trata de uma dimensão vivida pelo corpo: o meio existencial de ter e de viver no espaço.

Da profundidade assim compreendida não se pode mais dizer que é "terceira dimensão". Para começar, se houvesse alguma dimensão, seria antes a primeira: só existem formas, planos definidos se for estipulado a que distância de mim se encontram suas diferentes partes. Mas uma dimensão primeira e que contenha as outras não é uma dimensão, ao menos no sentido ordinário de uma certa relação segundo a qual se mede. A profundidade assim compreendida é antes a experiência da reversibilidade das dimensões, de uma "localidade" global onde tudo é ao mesmo tempo [...] (MERLEAU-PONTY, 2004b, p. 35)

Por sua capacidade de engajar o corpo, a profundidade fomenta discussões na disciplina da arquitetura no sentido de como substanciar múltiplas experiências, encontros, relações, itinerários, topologias e espacialidades para o habitante. Ela traz abordagem especulativa para projetar e pensar a experiência em termos de projeto. Como oscilar o espaço longínquo-visível e o espaço próximo-tangível na arquitetura? Como criar uma distância potencial que envolva o habitante? Como criar obscuridade que engaja? Essas questões devem serem colocadas e discutidas como reflexões projetuais e plásticas para explorarem situações espaciais.

Revista online do Departamento de Arquitetura e Urbanismo da Pontifícia Universidade Católica do Rio de Janeiro - PUC-Rio, Brasil Ano 8 - No으 9 - ISSN 2446-7340 


\section{Notas de fim:}

1. Este texto é um desdobramento de: VIEIRA, Yasmin Elganim. Uma arquitetura ao corpo: investigações sobre a profundidade fenomenológica para a potencialização da percepção no espaço construído. Orientação: Stéphane Huchet. Dissertação (Mestrado na área de Teoria, Produção e Experiência do Espaço e linha de pesquisa Teoria e História da Arquitetura e do Urbanismo e suas relações com outras Artes e Ciências) - Programa de Pós Graduação em Arquitetura e Urbanismo (NPGAU), Escola de Arquitetura da Universidade Federal de Minas Gerais (EA-UFMG), Belo Horizonte, 2020.

\section{Referências Bibliográficas:}

BENJAMIN, Walter. A obra de arte na era de sua reprodutibilidade técnica. Tradução: Gabriel Valladão Silva. São Paulo: Coleção L\&PM Pocket, 2013.

DIDI-HUBERMAN, Georges. O que vemos o que nos olha. 2 ed. Tradução: Paulo Neves. São Paulo: Editora 34, 2010.

MERLEAU-PONTY, Maurice. Fenomenologia da percepção. 4. ed. Tradução: Carlos Alberto Ribeiro de Moura. São Paulo: Martins Fontes, 2011.

. O visivel e o invisivel. 4. ed. Tradução: José Artur Giannoti e Armando Mora. São Paulo: Perspectiva, 2000.

. O olho e o espírito. Tradução: Paulo Neves e Maria Ermantina Galvão Gomes Pereira. São Paulo: Cosac \& Naify, 2004a.

. O olho e o espírito. In: . O olho e o espirito. Tradução: Paulo Neves e Maria Ermantina Galvão Gomes Pereira. São Paulo: Cosac \& Naify, 2004b, p. 13-46.

. A dúvida de Cézanne. (1945). In: . O olho e o espirito. Tradução: Paulo Neves e Maria Ermantina Galvão Gomes Pereira. São Paulo: Cosac \& Naify, 2004c, p. 121-162. 